\title{
Seasonal Flavonoid Profile and Kaempferitrin Content in the Leaf Extracts of Bauhinia forficata Subspecies forficata from Two Locations in Southeastern Brazil
}

\author{
João B. F. Tostes ${ }^{1}$, Antonio C. Siani ${ }^{*}$, Sérgio S. Monteiro², Vinicius F. Melo ${ }^{3}$, Jéssica 0. Costa ${ }^{3}$, \\ Ligia M. M. Valente ${ }^{3}$
}

${ }^{1}$ Department of Natural Products, Oswaldo Cruz Foundation, Rio de Janeiro, Brazil

${ }^{2}$ Forum Itaboraí, Oswaldo Cruz Foundation, Petrópolis, Brazil

${ }^{3}$ Chemistry Institute, Federal University of Rio de Janeiro, Rio de Janeiro, Brazil

Email: *antonio.siani@far.fiocruz.br

How to cite this paper: Tostes, J.B.F., Siani, A.C., Monteiro, S.S., Melo, V.F., Costa, J.O. and Valente, L.M.M. (2019) Seasonal Flavonoid Profile and Kaempferitrin Content in the Leaf Extracts of Bauhinia forficata Subspecies forficata from Two Locations in Southeastern Brazil. American Journal of Plant Sciences, 10, 208-220.

https://doi.org/10.4236/ajps.2019.101016

Received: December 11, 2018

Accepted: January 19, 2019

Published: January 22, 2019

Copyright $\odot 2019$ by author(s) and Scientific Research Publishing Inc. This work is licensed under the Creative Commons Attribution International License (CC BY 4.0).

http://creativecommons.org/licenses/by/4.0/

\section{(c) (i) Open Access}

\begin{abstract}
The leaves of Bauhinia forficata L. (Fabaceae) are used in Brazilian folk medicine mainly as antidiabetic agent. They are rich in polyphenols, and kaempferitrin and other flavonoids are currently considered as basic chemical criteria for the quality and the effectiveness of extracts and phytopharmaceuticals derived from them. Aiming to expand the scope of current data of the chemical profile of $B$. forficata subsp. forficata, the present study employed HPLC-DAD and HPLC-DAD-ESI/MS to compare the flavonoid profile and kaempferitrin content in the leaves of specimens collected seasonally during one year, in two different locations in Southeastern Brazil: Rio de Janeiro (RJ) and São Paulo (SP) states. The data showed a variation in the flavonoid profile and in the kaempferitrin content depending on the place of collection and the season of the year. The target compound, kaempferitrin, was found to be only a minor constituent in RJ $(0.21-1.02 \mu \mathrm{g} / \mathrm{mg})$, and was mostly absent or occurred as trace in SP location $(0.00-0.12 \mu \mathrm{g} / \mathrm{mg})$. Some degree of similarity was observed in the flavonoid profiles according to the region of collection. In agreement with some published reports, the low and quite variable kaempferitrin content as well the wide variability of the flavonoid profiles brings into question the dubious matter of using these compounds as chemical markers for this medicinal species.
\end{abstract}

\section{Keywords}

Bauhinia forficata, Kaempferitrin, Flavonoids, HPLC-DAD 


\section{Introduction}

Bauhinia forficata Link (Fabaceae) is a medium-sized tree found in Southeastern and Southern Brazil, popularly known as pata-de-vaca (cow's hoof) due to the bilobed shape of its leaves [1]. These leaves are used in the folk medicine in Brazil and other South American countries as helping in diabetes treatment insofar it presents a noteworthy anti-hyperglycemic action [2] [3] [4] [5] [6]. Currently, the Brazilian Health Ministry rolls this species among the priorities ones for scientific validation, toward developing a sugar-lowering phytopharmaceutical [7].

A number of studies have demonstrated the antidiabetic property of aqueous, alcoholic and aqueous-alcoholic extracts from the leaves of Bauhinia species [5] [8]. In the line, the researchers have striven to correlate the hypoglycemic effect to the chemical content of Bauhinia species, in particular the flavonoid-enriched fraction [9] and the individual constituent kaempferitrin (kaempferol-3,7-O- $\alpha$ dirhamnoside) (Figure 1) [10] [11].

Since it was firstly reported as a marked component in the methanolic extract of $B$. forficata leaves [12], the flavonoid kaempferitrin has drawn the attention as a possible responsible for the antihyperglycemic activity. This hypothesis was later proven correct when a significant hypoglycemic effect was observed in normal rats as well as in alloxan-induced diabetic animals, by administering different doses of kaempferitrin isolated from the hydroethanolic leaf extract of $B$. forficata, followed by solvent partitioning and flash column chromatography [13]. Kaempferitrin was then employed to assess the quality of $B$. forficata Link by quantifying such a compound in diverse hydroalcoholic extracts, an approach that included comparing leaves collected in different locales [14] as well as commercial dried samples [15]. However, kaempferitrin was not detected in every sample of $B$. forficata leaves thereafter approached. For instance, a NMR-based investigation on the constituents of the leaf hydroalcoholic extract led to the characterization of other 7-O-rhamnopyranosyl derivatives of kaempferol and quercetin, including di- and tri-glycosides [16]. Furthermore, the LC/ESI-MS analysis of the leaf extract of $B$. forficata did not reveal the presence of kaempferitrin but instead characterized four other quercetin and kaempferol glycosides as constituents [17].

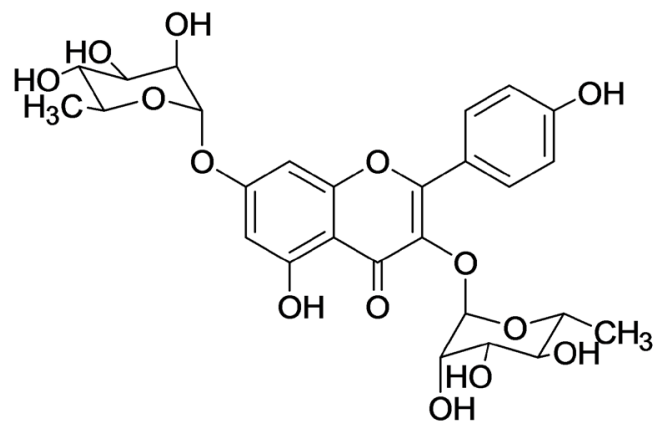

Figure 1. Structure of kaempferitrin. 
Ferreres et al. [18] by analyzing commercial and authentic samples of $B$. forficata towards $\alpha$-glucosidase inhibitory activity suggested that the higher amounts of quercetin derivatives found in some samples could be responsible for their higher activities when compared to those samples rich in kaempferol derivatives. On the other hand, Farag et al. [19] studying Egyptian Bauhinia spp. have observed by chemometric approaches no correlation between total flavonoid content and $\alpha$-glucosidase inhibition for $B$. forficata, which was speculated be related to the major content of flavonoid glycosides instead of free flavonoids. Furthermore, other kaempferol and quercetin glycosides were reported to be involved on the glucose-6-phosphatase inhibition effect of $B$. megalandra leaves [20] while a megastigmane glycoside from $B$. variegata was shown to increase insulin secretion [21]. Moreover, other compound present in the B. forficata leaf extract, as trigonelin, quercetin, rutin and other flavonol glycosides [22] [23], are endowed with antidiabetic activity [24].

There is nowadays a growing concern onto considering a polyphenols/flavonoid more unfolded profile to authenticate and control the quality of B. forficata samples. Efforts have been made to develop and apply analytical methods to establish the qualitative and/or quantitative polyphenolic compounds [17] [18] [25]. In such a context, dosing of kaempferitrin content remains relevant, regarding the background of this compound as hypoglycemic agent [14] [15] [26] [27]. Overall, the results have shown a wide variation on kaempferitrin content and polyphenolic profiles among commercial samples and those from different locations and seasons, including the two B. forficata subspecies: forficata and pruinosa [18] [25] [26] [27] [28] [29].

Previous studies involving the seasonal and/or location influence in the kaempferitrin content and the flavonoid profile and content of $B$. forficata leaves have been done with a single exemplar from each location or specific season [14] [15] [18] [26] [29]. In order to contributing to expand the data of the chemical profile of $B$. forficata, the present study aims at comparing the flavonoid profile and kaempferitrin content in leaves of the species seasonally collected during about one year in two different locations in Southeastern Brazil. Kaempferitrin quantification was achieved by HPLC-DAD. UPLC-ESI-MS was employed as complementary technique to putatively establish the kind of glycosides present in the extracts.

\section{Materials and Methods}

\subsection{Chemicals}

Analytical grade methanol $(\mathrm{MeOH})$, formic acid $(\mathrm{HCOOH})$ and HPLC grade acetonitrile $\left(\mathrm{CH}_{3} \mathrm{CN}\right)$ were purchased from Tedia-Brazil. Milli-Q grade water was used for HPLC and UPLC. The kaempferitrin used as reference compound was previously isolated from the leaves of Uncaria guianensis ( $99 \%$ purity) [30]. 


\subsection{Plant Material}

Leaves of Bauhinia forficata were collected from different trees in two different Brazilian sites: Valinhos city (SP, trees no 1 - 3) from July-2009 to February-2010 and Rio de Janeiro city (RJ, tree 4) from September-2009 to March-2011. The geographic coordinates are tree $n^{\circ} 1$ and tree $n^{\circ} 2: 22^{\circ} 57^{\prime} 44.6^{\prime \prime} \mathrm{S}, 46^{\circ} 59^{\prime} 39.8^{\prime \prime} \mathrm{W}$, alt. $692 \mathrm{~m}$; tree $\mathrm{n}^{\circ} 3: 22^{\circ} 58^{\prime} 40.8^{\prime \prime} \mathrm{S}, 46^{\circ} 57^{\prime} 23.0^{\prime \prime} \mathrm{W}$, alt. $807 \mathrm{~m}$ (SP, Valinhos); and tree no $4: 22^{\circ} 56^{\prime} 29.3^{\prime \prime S}, 43^{\circ} 24^{\prime} 20.16^{\prime \prime} \mathrm{W}$, alt. 25 m (RJ-Rio de Janeiro). All specimens were identified as Bauhinia forficata subsp. forficata by the specialist Dr. Angela S. F. Vaz from the Research Institute of Rio de Janeiro Botanical Garden (JBRJ). Voucher specimens are deposited in the JBRJ Herbarium under registrations RB-537536, RB-537541, RB-537544, RB-537545 (SP samples) and RB-511138 (RJ samples). Authorization for legal access to the genetic heritage was protocoled under no A66DDE3.

\subsection{Preparation of the Extracts}

The extracts were prepared using a modified procedure previously developed to assess the kaempferitrin content from the leaves of Uncaria guianensis [23]. After drying at room temperature, grinding in a stainless-steel blender and then sieving to particle size $\leq 0.177 \mathrm{~mm}, 250 \mathrm{mg}$ of $B$. forficata leaves were extracted with $9.5 \mathrm{~mL}$ of $\mathrm{MeOH}$ with ultrasound assistance for $18 \mathrm{~min}$. The mixture was centrifuged, the supernatant was separated, and the process repeated five times. The supernatants were pooled, and the solvent was evaporated under low pressure. Extract yields were determinate on dried weight.

\subsection{HPLC-DAD Analyses}

The HPLC analyses were performed using Shimadzu (VP) equipment with two pumps LC-10AD, auto-sampler SIL-10AD, column oven CTO-10A, vacuum degasser DGU-14A and diode-array detector Shimadzu SPD-M10A. A reverse-phase column Lichrocart Lichrospher $5 \mu \mathrm{m}, 250 \times 4 \mathrm{~mm}$ i.d. (Merck) coupled to a pre-column LiChrospher $100 \mathrm{RP} 18 \mathrm{e} 5 \mu \mathrm{m}, 4 \times 4 \mathrm{~mm}$ was used. Elution was performed in a gradient mode at a $1.0 \mathrm{~mL} / \mathrm{min}$ flow with $\mathrm{CH}_{3} \mathrm{CN}$ (solvent $\mathrm{B}$ ) and $\mathrm{H}_{2} \mathrm{O} / \mathrm{HCOOH}, \mathrm{pH} 3$ (solvent $\mathrm{A}$ ): 0 - 30 min 95\% - 75\% solvent $\mathrm{A}$, 30 - 50 min $75 \%$ - $20 \%$ solvent A, 50 - 55 min 20\% - 95\% solvent A and finally 55 - 60 min 95\% solvent A. The diode-array detector was set at an acquisition range of $200-600 \mathrm{~nm}$. The chromatograms were monitored at $265 \mathrm{~nm}$, the injected volume was $40 \mu \mathrm{L}$ and the oven column was set at $30^{\circ} \mathrm{C}$. $\mathrm{MeOH}$ solutions of the crude extracts at $c=15 \mathrm{mg} / \mathrm{mL}$ were filtered through $0.45 \mu \mathrm{m}$ Minisart RC25 membranes (Sartorius) and then injected in duplicate. The kaempferitrin quantification was done through an external calibration curve using aprevious isolated sample (Section 2.1). Five concentration levels of the reference compound were prepared in methanol $(1.30,2.60,9.75,32.30$ and $65.00 \mu \mathrm{g} / \mathrm{mL})$. Each level was injected in triplicate to yield the calibration curve $\left(\mathrm{R}^{2}=0.9999\right)$ derived from the equation $y=87272 x-33684$, where $y$ is the peak area and $x$ the con- 
centration $(\mu \mathrm{g} / \mathrm{mL})$. Kaempferitrin in the extracts was quantified against this calibration curve. The results were later converted to $\mu \mathrm{g} / \mathrm{mg}$ extract. The linearity and validity of the calibration curve were supported by ANOVA test. The quantitation limit $(\mathrm{QL})$ was considered as the lowest point of the curve, i.e. 1.30 $\mu \mathrm{g} / \mathrm{mL}(0.09 \mu \mathrm{g} / \mathrm{mg})$. The confirmation of the kaempferitrin peak in the extracts was performed by fortification of three selected samples (SP-T1-JUL2009, SP-T2-DEC2009 and RJ-NOV2009) with $1-3 \mu \mathrm{L}$ of the reference compound in methanolat $c=130 \mu \mathrm{g} / \mathrm{mL}$. This value was calculated in order to enhance the original area by about three times. Two injections of each sample (original and fortified) were carried out and the respective area's integrations were used to corroborate the peak identity.

\subsection{HPLC-MS Analyses}

High-performance liquid chromatography-diode array detection/electrospray ionization mass spectrometry (HPLC-DAD-ESI/MS) analyses were performed using a Shimadzu Prominence-Nexera (Shimadzu, Japan) composed by a high-pressure binary pump LC-30AD and column oven CTO-30A. The system was equipped with a photodiode array detector (model SPD-M20A) and coupled to a quadrupole mass spectrometer MS ZQ (Micromass-Waters) equipped with an ESI source and an ion trap mass analyzer. Data were acquired using a CLASS-VP software, which was controlled by a CBM-20A interface. The following parameters were set in the negative ion mode: capillary voltage $3.0 \mathrm{KV}$, cone voltage $40.0 \mathrm{~V}$, extractor voltage $1.0 \mathrm{~V}$, RF lens $1.0 \mathrm{~V}$, source block temperature $150^{\circ} \mathrm{C}$, desolvation temperature $350^{\circ} \mathrm{C}$, cone $\mathrm{N}_{2}$ flow $10 \mathrm{~L} / \mathrm{h}$, desolvation $\mathrm{N}_{2}$ flow $300 \mathrm{~L} / \mathrm{h}$. Samples $(10 \mu \mathrm{L}$ injection volume) were injected into a RP-18 reversed-phase LiChrospher column $(125 \times 2.0 \mathrm{~mm} \times 5 \mu \mathrm{m}$ particle size $)$ (Merck) maintained at $35^{\circ} \mathrm{C}$. The elution conditions were as follows: 0.25 $\mathrm{mL} /$ minflow rate; solvent $\mathrm{A}$, water $\mathrm{pH} 3.0$ adjusted with formic acid and solvent $\mathrm{B}$ acetonitrile. The gradient was: 0 - $15 \mathrm{~min}$, linear 5\% - 25\% B; $15-25 \mathrm{~min}$, linear 25\% - 80\% B; 25 - $27.5 \mathrm{~min}$, linear $80 \%-5 \%$ B; 27.5 - $30 \mathrm{~min}$, isocratic $5 \%$ B. The DAD was programmed in the range $190-600 \mathrm{~nm}$ with resolution at the level of $4 \mathrm{~nm}$. Mass acquisition was set in the range m/z $100-1000$ (resolution 0.4). The system was calibrated with standard kaempferitrin ( $\mathrm{m} / \mathrm{z} 577.0)$. The two more representative samples from each locale, in terms of kaempferitrin concentration, were analyzed.

\section{Results and Discussion}

In our study, evaluation of the flavonoid profile and kaempferitrin content in $B$. forficata subsp. forficata leaves was carried out with plants collected seasonally during approximately one year in two different places of the Brazilian Southeast region, with differing altitude and climate (seaside town of Rio de Janeiro, RJ and Valinhos in the interior of São Paulo, SP]. The extract yields, although not-statistically considered, pointed to lower amounts and greater variation in 
the samples from SP than those from RJ (Table 1). The HPLC-DAD chromatograms of the extracts from the several collections showed a steady qualitative profile in the RJ samples and a noticeable variation in the flavonoid profile in the SP samples. No correlation between the chemical profiles and time of collection or different trees was observed, although some chromatograms similarity could be inferred regarding the site of collection (Figure 2).

Table 1. Methanol extract yields and kaempferitrin content in leaves of Bauhinia forficata subsp. forficata seasonally collected in two different localites in Brazil.

\begin{tabular}{|c|c|c|c|}
\hline Sample code & Extract weight $(\mathrm{mg})$ & Extract yield $(\%)^{1}$ & $\begin{array}{c}K F \text { content in the extract } \\
(\mu \mathrm{g} / \mathrm{mg})\end{array}$ \\
\hline \multicolumn{4}{|c|}{ Collection in Valinhos (SP state) } \\
\hline SP-T1-JUL2009 & 29.5 & 11.8 & $0.12 \pm 0.00$ \\
\hline$S P-T 1-A U G 2009$ & 15.3 & 6.0 & $<\mathrm{QL}$ \\
\hline$S P-T 1-S E P 2009$ & 15.1 & 6.0 & $<\mathrm{QL}$ \\
\hline$S P-T 1-N O V 2009$ & 11.3 & 4.5 & $<\mathrm{QL}$ \\
\hline$S P-T 1-D E C 2009$ & 20.6 & 7.9 & $<\mathrm{QL}$ \\
\hline$S P-T 1-J A N 2010$ & 26.3 & 10.5 & $<\mathrm{QL}$ \\
\hline$S P-T 2-A U G 2009$ & 10.0 & 4.0 & $<\mathrm{QL}$ \\
\hline$S P-T 2-S E P 2009$ & 25.3 & 10.0 & $0.09 \pm 0.01$ \\
\hline$S P-T 2-N O V 2009$ & 25.7 & 10.3 & $0.12 \pm 0.03$ \\
\hline$S P-T 2-D E C 2009$ & 15.2 & 6.0 & $<\mathrm{QL}$ \\
\hline$S P-T 2-J A N 2010$ & 36.3 & 14.3 & $<\mathrm{QL}$ \\
\hline$S P-T 3-A U G 2009$ & 27.2 & 10.9 & $0.10 \pm 0.01$ \\
\hline SP-T3-SEP2009 & 21.3 & 8.4 & $<\mathrm{QL}$ \\
\hline$S P-T 3-N O V 2009$ & 30.8 & 12.2 & ND \\
\hline$S P-T 3-D E C 2009$ & 16.1 & 6.4 & ND \\
\hline$S P-T 3-J A N 2010$ & 36.0 & 14.0 & $<\mathrm{QL}$ \\
\hline$S P-T 3-F E B 2010$ & 42.7 & 16.9 & $<\mathrm{QL}$ \\
\hline \multicolumn{4}{|c|}{ Collection in Rio de Janeiro (RJ state) } \\
\hline$R J-S E P 2009$ & 45.9 & 18.4 & $0.21 \pm 0.02$ \\
\hline RJ-NOV2009 & 44.7 & 17.8 & $0.22 \pm 0.00$ \\
\hline RJ-DEC2009 & 54.1 & 21.1 & $0.57 \pm 0.05$ \\
\hline$R J-J A N 2010$ & 44.6 & 17.4 & $0.32 \pm 0.00$ \\
\hline$R J-M A R 2010$ & 42.2 & 16.4 & $0.24 \pm 0.01$ \\
\hline$R J-F E B 2011$ & 30.0 & 12.0 & $0.59 \pm 0.04$ \\
\hline$R J-M A R 2011$ & 45.0 & 18.0 & $1.04 \pm 0.01$ \\
\hline
\end{tabular}

${ }^{1}$ Related to $250 \mathrm{mg}$ of leaves; KF $=$ kaempferitrin; $\mathrm{QL}=$ Quantitation Limit $=0.09 \mu \mathrm{g} / \mathrm{mg}$. ND = notdetected; $\mathrm{T} 1, \mathrm{~T} 2$ and $\mathrm{T} 3=$ trees 1,2 and 3 , respectively (see item 2.2 ). 


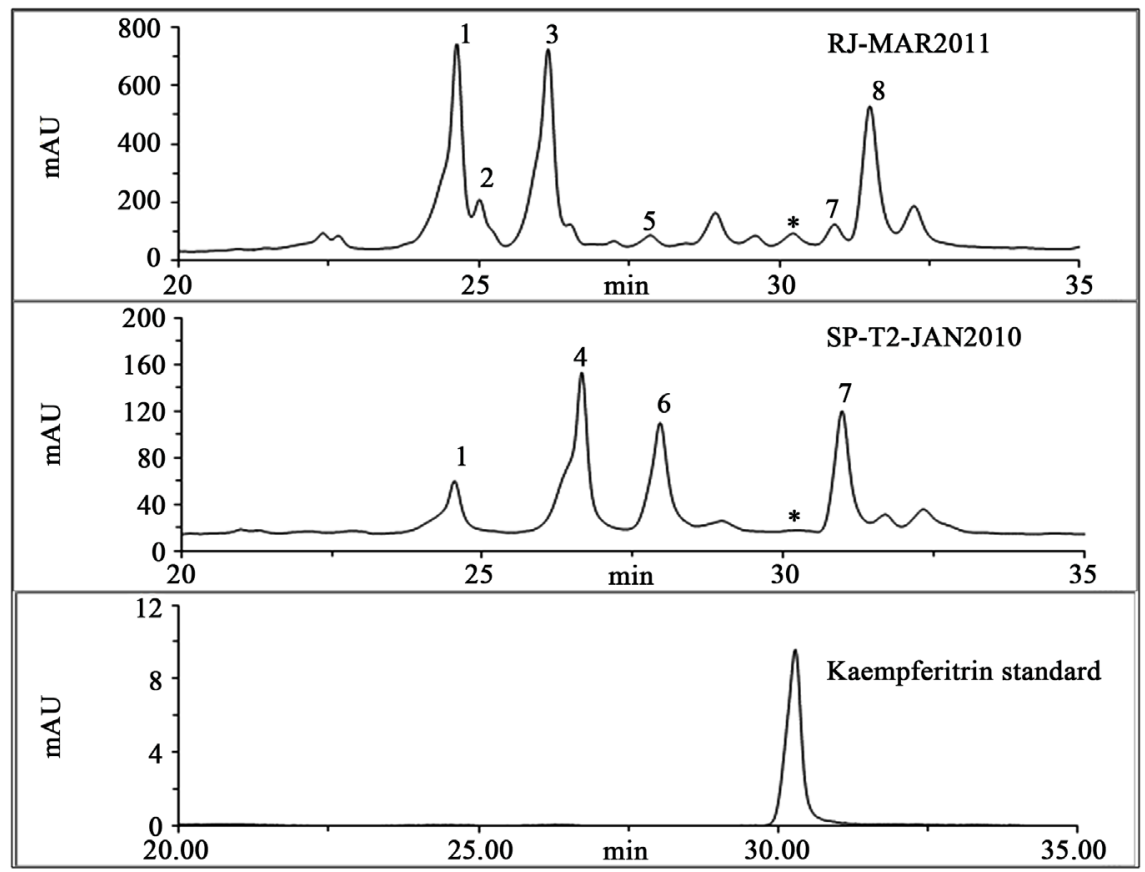

Figure 2. Comparison of typical HPLC-DAD flavonoid profiles of Bauhinia forficata subsp. forficata leaves according to collection in Rio de Janeiro (RJ-MAR2011) and Valinhos (SP-T3-AUG2009) at $265 \mathrm{~nm}$. See Table 2 for peak characterization. ${ }^{\star} \equiv$ kaempferitrin signal.

The presence of kaempferitrin in the extracts was indicated by matching its retention time $\left(R_{\mathrm{t}}=30.2 \mathrm{~min}\right)$ and identity of the UV-spectrum with the reference compound, moreover than being thereafter confirmed by the fortification procedures. The kaempferitrin content in $B$. forficata leaf extracts varied from 0.21 to $1.04 \mu \mathrm{g} / \mathrm{mg}$ for RJ specimens, and was mostly absent or occurred as trace compounds in the SP samples. Most of these latter collections resulted extracts containing amounts of kaempferitrin below the quantitation limit $(0.09 \mu \mathrm{g} / \mathrm{mg})$. In these cases, the contents of kaempferitrin could be inferred from the calibration curve; however, such an extrapolation was eventually considered worthless (Table 1).

Overall, our data corroborates some previously reports on the chemical variability of the flavonoid profile in B. forficata leaves [14] [19] [25]. The extracts approached in this study showed the predominance of glycosylated flavonols, which were primarily characterized by their $R_{\mathrm{t}}$ (based on the $R_{\mathrm{t}}$ of kaempferitrin used as reference) and by their UV spectra as derivatives of kaempferol $\left(\lambda_{\mathrm{MAX}} \sim 265 \mathrm{~nm}\right)$, quercetin or isorhamnetin or myricetin $\left(\lambda_{\mathrm{MAX}} \sim 255 \mathrm{~nm}\right)$ [31] (Figure 2). All these compounds have been previously described in the leaves of this species [17] [18] [23] [25]. Yet, erratic concentrations [26] [32] or even the absence [17] of kaempferitrin in B. forficata leaves from diverse geographical origins has already been reported during the development and validation of spectrometric methods to quantify the flavonoid pool in this plant matrix.

Also in accordance with the literature, most of flavonoid constituents-herein 
emphasizing the major ones-were kaempferol derivatives. The degree of the aglycones glycosylation was suggested by the quasi molecular ion $[\mathrm{M}-\mathrm{H}]^{-} \mathrm{ob}-$ tained from the UPLC-ESI-MS operating in the negative mode (Table 2). In most of the cases, the UV-suggested aglycones were corroborated by the occurrence of their respective fragment in the mass spectrum. These results align well with those obtained from the detailed analysis performed by Ferreres et al. when approaching the leaves of $B$. forficata from Southern Brazilian, using a variation of the same technique employed here [18].

Some researchers have also caught the attention to the unavailability of reports on antidiabetic activity of other kaempferol glycosides that are usually present in the B. forficata extracts [16] [26] [33]. Thereby, the emerging question concerns to achieve a steady and reproducible chromatographic profile, based on either an individual compound or a group of phenolics, aiming at establishing a fingerprint to refer the quality of the raw material, herbal drug or phytopharmaceutical derived from this important medicinal species. As being a current issue in this standardizing context, the virtual absence of kaempferitrin in the extracts has to be carefully considered. In spite of the some advances in the quality control of the raw material, developing medicinal products from this species requires extending studies in order to achieve the optimum correlation between efficacy and chemical profile for B. forficata extracts. Additionally, it is well known that environmental factors such as seasonality, circadian rhythm, radiation, temperature, altitude and humidity can modify the secondary metabolism thus interfering quantitatively and qualitatively in the production of

Table 2. UV and MS data of some flavonoids from leaf methanol extracts of Bauhinia forficata subsp. forficata from two different localities in Brazil.

\begin{tabular}{ccccc}
\hline Peak $^{1}$ & $\mathrm{Rt}(\min )$ & $\lambda_{\max }(\mathrm{nm})$ & {$[\mathrm{M}-\mathrm{H}]^{-}(\mathrm{m} / \mathrm{z})^{3}$} & Suggested Structure $^{4}$ \\
\hline $1+2$ & 24.6 & 265,346 & 755.3 & K-triglycoside \\
2 & 26.2 & 265,346 & 739.2 & K-triglycoside \\
3 & 26.6 & 265,346 & 739.2 & K-triglycoside \\
4 & 27.9 & 255,351 & 609.1 & Q-diglycoside \\
5 & 28.9 & 253,353 & 463.1 & Q-glycoside \\
$\left({ }^{*}\right)^{2}$ & 30.2 & 266,352 & 577.3 & Kaempferitrin \\
6 & 30.9 & 266,346 & 593.3 & K-diglycoside \\
7 & 31.5 & 255,352 & 623.2 & I-diglycoside \\
8 & 32.2 & 254,348 & 447.1 & Q-glycoside \\
Standard KF & 30.3 & 264,346 & 577.3 & K-diglycoside \\
\hline
\end{tabular}

${ }^{1}$ For peak numbering see Figure 2. Peaks 1 and 2 afforded identical UV spectra, but were not separated in the HPLC-MS experiment. ${ }^{2}$ Trace level in most of the SP samples (see text). $\mathrm{K}=$ kaempferol, $\mathrm{Q}=$ quercetin, $\mathrm{I}=$ isorhamnetin. ${ }^{3} \mathrm{LC}-\mathrm{ESI}-\mathrm{MS}$ in negative mode applied to samples RJ-MAR2011 and SP-T3-AUG2009 (see experimental and Table 1). Excepting peak 7 (20\%), all others showed [M-H]- ion as the base peak. ${ }^{4}$ Based on the UV typical profiles [31] and comparing MS data with those reported in [18] and [27]; $\mathrm{K}=$ kaempferol; $\mathrm{Q}=$ quercetin, $\mathrm{I}=$ isorhamnetin. Most spectra showed fragments corresponding to $\mathrm{K}(\mathrm{m} / \mathrm{z} 283)$ or $\mathrm{Q}$ $(\mathrm{m} / \mathrm{z}$ 301) aglycones. 
compounds by the plant [34]. Also stressing conditions from oxidative or hydric unbalance, for instance, can modify the plants biosynthetic pathway and induce them to produce chemical defenses in response to changes in the habitat [35] [36]. All these nuances have to be duly considered when aiming standardization of medicinal extracts [37].

Finally yet importantly, most of the early reports in the literature on chemical and biological properties of $B$. forficata Link have approached such a species as a particular botanical entity, disregarding possible morphological distinctions that encompass, for instance, subspecies or possible varieties. In this context, taxonomic studies have been gradually evolve toward consolidating two subspecies growing in Brazil: Bauhinia forficata Link subsp. forficata and Bauhinia forficata subsp. pruinosa (Vogel) Fortunato \& Wunderlin [38] [39] [40]. Both of these thrive in the Brazilian Atlantic forest, with the latter being more densely reported in southern areas and frontier countries. Conversely, the former one spreads along the upside subequatorial forest, eventually appearing in Northeastern tropical areas [40].

Recent compilation in the literature reveals that researchers have been alert to considering such a taxonomic detail [17] [18] [22] [27]. However, with rare exceptions [22], such data usually do not accompany the set of information provided during the sale of plant raw material and the subspecies identification remains lacking in some reports elsewhere [23] [41]. On comparing the flavonoid profile of Bauhinia forficata subsp. pruinosa and a commercial sample of Bauhinia forficata (non-determined subspecies), Ferreres et al. demonstrated their quite different phenolic profiles, particularly concerning to the content and type of glycosylated aglycones present in each one. This feature was also suggested by the authors as implying of distinct levels of biological responses [18]. The present study is the first to approach the polyphenol profile of $B$. forficata subsp. forficata botanically certified.

\section{Concluding Remarks}

The data presented in this study show the complex question of considering the phenolic content of Bauhinia forficata leaves-be it the flavonoid profile or another phenolic group profile, or even an individual compound-as a tool to the quality control of the vegetal raw material, herbal and phytopharmaceutical derived from this species. Additionally, the spontaneous growth of two B. forficata subspecies regarded as anti-hyperglycemic also demonstrates the need for a precise botanical classification when approaching medicinal properties of this species. Further studies on the correlation between the chemical composition and therapeutic property of this important antidiabetic species are necessary.

\section{Acknowledgements}

VFM and JOC thank CNPq-Brazil for their fellowships. The authors are indebted to Dr. J. L. Mazzei for his valuable suggestions. 


\section{Conflicts of Interest}

The authors declare no conflicts of interest concerning the present publication.

\section{References}

[1] Lorenzi, H. and Matos, F.J.A. (2008) Plantas Medicinais no Brasil: Nativas e exóticas. Instituto Plantarum de Estudos da Flora LTDA, Nova Odessa.

[2] Cechinel, V.F. (2009) Chemical Composition and Biological Potential of Plants from the Genus Bauhinia. Phytotherapy Research, 23, 1347-1354. https://doi.org/10.1002/ptr.2756

[3] Nogueira, A.C. and Sabino, C.V.S. (2012) Revision of the Genus Bauhinia Addressing the Scientific Aspects of Species Bauhinia forficata Link and Bauhinia variegata L. of Interest to the Pharmaceutical Industry. Revista Fitos, 7, 77-84.

[4] Trojan-Rodrigues, M., Alves, T.L.S., Soares, G.L.G. and Ritter, M.R. (2012) Plants Used as Antidiabetics in Popular Medicine in Rio Grande do Sul, Southern Brazil. Journal of Etnopharmacology, 139, 155-163. https://doi.org/10.1016/j.jep.2011.10.034

[5] Batista, P.N., Oliveira, T.C., Leal, F.R., Batista, A.N., Medeiros, M.G.F. and Nunes, L.C.C. (2013) The Influence of Using Bauhinia forficata Link in Glycemic, Lipid and Toxicological Profile in in Vivo Experimental Models: A Systematic Review. Journal of Medicinal Plants Research, 7, 2343-2348.

[6] Silva, M.I.G., Melo, C.T.V., Vasconcelos, L.F., Carvalho, A.M.R. and Sousa, F.C.F. (2012) Bioactivity and Potential Therapeutic Benefits of Some Medicinal Plants from the Caatinga (Semi-Arid) Vegetation of Northeast Brazil: A Review of the Literature. Revista Brasileira de Farmacognosia, 22, 193-207.

https://doi.org/10.1590/S0102-695X2011005000171

[7] Brasil (2009) RENISUS-Relação Nacional de Plantas Medicinais de Interesse ao SUS. Espécies vegetais.

http://portal.saude.gov.br/portal/arquivos/pdf/RENISUS.pdf

[8] Salgueiro, A.C.F., Leal, C.Q., Bianchini, M.C., Prado, I.O., Mendez, A.S.L., Puntel, R.L., Folmer, V., Soares, F.A., Avila, D.S. and Puntel, G.O. (2013) The Influence of Bauhinia forficata Link subsp. pruinosa Tea on Lipid Peroxidation and Non-Protein SH Groups in Human Erythrocytes Exposed to High Glucose Concentrations. Journal of Ethnopharmacology, 148, 81-87. https://doi.org/10.1016/j.jep.2013.03.070

[9] Silva, F.R.M.B., Szpoganicz, B., Pizzolatti, M.G., Willrich, M.A.V. and de Sousa, E. (2002) Acute Effect of Bauhinia forficata on Serum Glucose Levels in Normal and Alloxan-Induced Diabetic Rats. Journal of Ethnopharmacology, 83, 33-37. https://doi.org/10.1016/S0378-8741(02)00193-9

[10] Jorge, A.P., Horst, H., de Sousa, E., Pizzolatti, M.G. and Silva, F.R.M.B. (2004) Insulinomimetic Effects of Kaempferitrin on Glycemia and on 14C-Glucose Uptake in rat Soleus Muscle. Chemico-Biological Interactions, 149, 89-96. https://doi.org/10.1016/j.cbi.2004.07.001

[11] Sousa, E., Zanatta, L., Seifriz, I., Creezynski-Pasa, T.B., Pizzolatti, M.G., Szpoganiez, B. and Silva, F. (2004) Hypoglycemic Effect and Antioxidant Potential of Kaempferol-3,7-O-(alpha)-dirhamnoside from Bauhinia forficata Leaves. Journal of Natural Products, 67, 829-832. https://doi.org/10.1021/np030513u

[12] da Silva, K.L., Biavatti, M.W., Leite, S.N., Yunes, R.A., Delle Monache, F. and Cechinel Filho, V. (2000) Phytochemical and Pharmacognostic Investigation of Bau- 
hinia forficata Link (Leguminosae). Zeitschrift für Naturforschung C, 55, 478-480. https://doi.org/10.1515/znc-2000-5-627

[13] de Sousa, E., Zanatta, L., Seifriz, I., Creczynski-Pasa, T.B., Pizzolatti, M.G., Szpoganicz, B. and Silva, F.R.M.B. (2004) Hypoglycemic Effect and Antioxidant Potential of Kaempferol-3,7-O-( $\alpha$ )-dirhamnoside from Bauhinia forficata Leaves. Journal of Natural Products, 67, 829-832. https://doi.org/10.1021/np030513u

[14] Pinheiro, T.S.D.B., Johansson, L.A.P., Pizzolatti, M.G. and Biavatti, M.W. (2006) Comparative Assessment of Kaempferitrin from Medicinal Extracts of Bauhinia forficata Link. Journal of Pharmaceutical and Biomedical Analysis, 41, 431-436. https://doi.org/10.1016/j.jpba.2005.12.010

[15] Engel, I.C., Ferreira, R.A., Cechinel-Filho, V. and Meyre-Silva, C. (2008) Quality Control of Drugs from Bauhinia forficata Link (Fabaceae). Revista Brasileira de Farmacognosia, 18, 258-264. https://doi.org/10.1590/S0102-695X2008000200021

[16] Pizzolatti, M.G., Cunha Jr., A., Szpoganicz, B., Sousa, E.D., Braz-Filho, R. and Schripsema, J. (2003) Flavonoids Glycosides from Leaves and Flowers of Bauhinia forficata (Leguminosae). Química Nova, 26, 466-469. https://doi.org/10.1590/S0100-40422003000400003

[17] Farias, L.D.S. and Mendez, A.S. (2014) LC/ESI-MS Method Applied to Characterization of Flavonoids Glycosides in B. forficata subsp. pruinosa. Quimica Nova, 37, 483-486. https://doi.org/10.5935/0100-4042.20140069

[18] Ferreres, F., Gil-Izquierdo, A., Vinholes, J., Silva, S.T., Valentão, P. and Andrade P.B. (2012) Bauhinia forficata Link Authenticity Using Flavonoids Profile: Relation with Their Biological Properties. Food Chemistry, 134, 894-904.

https://doi.org/10.1016/j.foodchem.2012.02.201

[19] Farag, M.A., Sakna, S.T., El-fiky, N.M., Shabana, M.M. and Wessjohann, L.A. (2015) Phytochemical, Antioxidant and Antidiabetic Evaluation of Eight Bauhinia L. Species from Egypt Using UHPLC-PDA-qTOF-MS and Chemometrics. Phytochemistry, 119, 41-50. https://doi.org/10.1016/j.phytochem.2015.09.004

[20] González-Mujica, F. (2011) Antihiperglycaemic Activity of Bauhinia megalandra. In: Rasooli, I., Ed., Phytochemicals-Bioactivities and Impact on Health, InTech, Croatia, 333-356. https://doi.org/10.5772/27219

[21] Frankish, N., Menezes, F.S., Mills, C. and Sheridan, H. (2010) Enhancement of Insulin Release from the $\beta$-Cell Line INS-1 by an Ethanolic Extract of Bauhinia variegata and Its Major Constituent Roseoside. Planta Medica, 76, 995-997. https://doi.org/10.1055/s-0029-1240868

[22] Toloza-Zambrano, P., Avello, M. and Fernández, P. (2015) Determinación de rutina y trigonelina en extractos de hojas de Bauhinia forficata subsp. pruinosa y evaluación del efecto hipoglicemiante en humanos. Boletín Latinoamericano y del Caribe de Plantas Medicinales y Aromáticas, 14, 1.

[23] Miceli, N., Buongiorno, L.P., Celi, M.G., Cacciola, F., Dugo, P., Donato, P., Mondello, L., Bonacorsi, I. and Taviano, M.F. (2016) Role of the Flavonoid-Rich Fraction in the Antioxidant and Cytotoxic Activities of Bauhinia forficata Link. (Fabaceae) Leaves Extract. Natural Product Research, 30, 1229-1239. https://doi.org/10.1080/14786419.2015.1050671

[24] Da Cunha, A.M., Menon, S., Menon, R., Couto, A.G., Bürger, C. and Biavatti, M.W. (2010) Hypoglycemic Activity of Dried Extracts of Bauhinia forficata Link. Phytomedicine, 17, 37-41. https://doi.org/10.1016/j.phymed.2009.06.007

[25] Peixoto-Sobrinho, T.J.S., Gomes, T.L.B., Cardoso, K.C.M., Albuquerque, U.P. and Amorim, E.L.C. (2012) Teor de flavonóides totais em produtos contendo 
pata-de-vaca (Bauhinia L.) comercializados em farmácias de Recife/PE. Revista Brasileira de Plantas Medicinais, 14, 586-591. https://doi.org/10.1590/S1516-05722012000400003

[26] Marques, G.S., Leao, W.F., Lyra, M.A.M., Peixoto, M.S., Monteiro, R.P.M., Rolim, L.A., Xavier, H.S., Neto, P.J.R. and Soares, L.A.L. (2013) Comparative Evaluation of UV/VIS and HPLC Analytical Methodologies Applied for Quantification of Flavonoids from Leaves of Bauhiniaforficata. Revista Brasileira de Farmacognosia, 23, 51-57. https://doi.org/10.1590/S0102-695X2012005000143

[27] Santos, M., Fortunato, R.H. and Spotorno, V.G. (2018) Analysis of Flavonoid Glycosides with Potential Medicinal Properties on Bauhinia uruguayensis and Bauhinia forficata Subspecies pruinosa. Natural Product Research, 1-5.

[28] Arigony, A.L.V. (2005) Determinação química e biológica de Bauhinia forficata Link subespécie pruinosa (pata-de-vaca-Leguminosae). MSc Thesis, Universidade Federal do Rio Grande do Sul, Porto Alegre.

[29] Ardila, J.A., Funari, C.S., Andrade, A.M., Cavalheiro, A.J. and Carneiro, R.L. (2015) Cluster Analysis of Commercial Samples of Bauhinia spp. Using HPLC-UV/PDA and MCR-ALS/PCA without Peak Alignment Procedure. Phytochemical Analysis, 26, 367-373. https://doi.org/10.1002/pca.2571

[30] Paixão, D. (2010) Desenvolvimento por planejamento fatorial e validação de metodologia analítica utilizando extração em fase sólida e cromatografia líquida de alta eficiência na quantificação do flavonoide campferitrina em Uncaria guianensis (Rubiaceae). MSc Thesis, Universidade Federal do Rio de Janeiro.

[31] Mabry, T.J., Markham, K.R. and Thomas, M.B. (1970) The Systematic Identification of Flavonoids. Springer, Berlin. https://doi.org/10.1007/978-3-642-88458-0

[32] Marques, G.S., Monteiro, R.P.M., Leao, W.F., Lyra, M.A.M., Peixoto, M.S., Rolim-Neto, P.J., Xavier, H.S. and Soares, L.A.L. (2012) Evaluation of Procedures for Spectrophotometric Quantification of Total Flavonoids in Leaves of Bauhinia forficata Link. Química Nova, 35, 517-522. https://doi.org/10.1590/S0100-40422012000300014

[33] Marques, G.S., Lyra, M.A.M., Peixoto, M.S., Monteiro, R.P.M., Leao, W.F., Xavier, H.S., Soares, L.A.L. and Rolim, N.P.J. (2012) Phytochemical Characterization and Physical Chemistry of the Leaves of Bauhinia forficata Link Collected in Two Brazilian Regions. Revista de Ciências Farmacêuticas Básica e Aplicada, 33, 57-62.

[34] Gobbo-Neto, L. and Lopes, N.P. (2007) Plantas medicinais: Fatores de influência no conteúdo de metabólitos secundários. Química Nova, 30, 374-381. https://doi.org/10.1590/S0100-40422007000200026

[35] Dicke, M. and Hilker, M. (2003) Induced Plant Defences: From Molecular Biology to Evolutionary Ecology. Basic and Applied Ecology, 4, 3-14. https://doi.org/10.1078/1439-1791-00129

[36] Winkel-Shirley, B. (2002) Biosynthesis of Flavonoids and Effects of Stress. Current Opinion in Plant Biology, 5, 218-223. https://doi.org/10.1016/S1369-5266(02)00256-X

[37] Sahoo, N., Manchikanti, P. and Dey, S. (2010) Herbal Drugs: Standards and Regulation. Fitoterapia, 81, 462-471. https://doi.org/10.1016/j.fitote.2010.02.001

[38] Fortunato, R.H. (1986) Revision del genero Bauhinia (Cercideae, Caesalpinioidea, Fabaceae) para la Argentina. Darwiniana, 27, 527-557.

[39] Fortunato, R.H. (1996) Bauhinia affinis (Fabaceae) uma nueva cita para la flora Argentina. Darwiniana, 34, 405-409. 
[40] Vaz, A.M.S. and Tozzi, A.M.G. (2005) Synopsis of Bauhinia sect. Pauletia (Cav.) DC. (Leguminosae: Caesalpinioideae: Cercideae) in Brazil. Brazilian Journal of Botany, 28, 477-491. https://doi.org/10.1590/S0100-84042005000300006

[41] Moranza, H.G., Scanavaca Junior, L., Mataqueiro, M.I. and Ferraz, G. (2017) Chronic Administration of Bauhinia forficata Link Reduced Exploratory Activity without Affecting Blood Glucose in Healthy Rats. Plant, 5, 27-32. 